\title{
Laparoscopic Surgery for Intra-abdominal Ruptured Liver Abscess: A study of 32 cases
} \author{
and Nguyen Quoc Vinh ${ }^{7}$ \\ ${ }^{1}$ Radiology Department, Ha Noi Medical University, Vietnam \\ ${ }^{2}$ Department of Health, Ministry of Public Security, Vietnam \\ ${ }^{3}$ Surgery Department, Cho Ray hospital, Vietnam \\ ${ }^{4}$ National Otorhinolaryngology Hospital of Vietnam \\ ${ }^{5}$ Radiology Department, Pham Ngoc Thach University of Medicine and HCMC Oncology Hospital, Vietnam \\ ${ }^{6}$ Radiology Department, HCMC Medical and Pharmacy University \\ ${ }^{7}$ General Surgery Department, HCMC Medical and Pharmacy University Hospital
}

Pham Hong Duc ${ }^{1 *}$, Le Quang Minh ${ }^{2}$, Le Cong Tri ${ }^{3}$, Vu Thi Minh Thuc ${ }^{4}$, Huynh Quang Huy ${ }^{5}$, Ho Hoang Phuong

Received: May 27, 2019; Published: June 25, 2019

*Corresponding author: Pham Hong Duc, Radiology Department, Ha Noi Medical University, Vietnam

Abstract

Objectives: The purpose of this study is to see the efficacy of laparoscopic treatment in the management of intra-abdominal ruptured liver abscess.

Patients and Methods: From 2014 to 2018, 32 patients with intra-abdominal ruptured liver abscess meeting entry criteria received laparoscopic surgical management in our hospital. Clinical data including operation time, postoperative complication rate, length of postoperative hospital stay was retrospectively analyzed.

Results: 32 patients with a median age of $53.3 \pm 15.3$ years (range, $24-85$ years). The mean of operating time was $105 \pm 28$ minutes (median 100 minutes, range: 60 - 185 minutes). Time to pass gas after surgery was 2,8 $\pm 1,6$ days in average (range: 1 - 6 days). The mean of time to remove drains was $10 \pm 5$ days (range: 3 - 27 days). The mean time of post-operative stay was 12,5 $\pm 6,9$ days (rang: 3 - 30 days). Postoperative complications occurred in 8 patients (25.0\%) (3 cases of local ascite, 2 cases of pneumoniae, 1 case wound bleeding, 1 bile duct leak, 1 wound infection), and all complications were successfully managed.

Conclusion: Laparoscopic drainage is highly effective in management of large and freely ruptured abscess with decreased mortality, postoperative recovery and complications

Keywords: Liver Abscess, Ruptured, Laparoscopic

\section{Introduction}

Liver abscess is a common condition in tropical countries and is associated with significant morbidity and mortality. Traditionally, there are two major classifications of hepatic abscess; pyogenic and amoebic $[1,2]$. There are various complications associated with hepatic abscesses, of which, rupture of the abscess is the most common [3-5]. Intraperitoneal rupture of liver abscess is a rare but potentially fatal disease, often involving the elderly, who are commonly of poor surgical risk with background of significant medical illness [6,7]. Accurate preoperative diagnosis is difficult and often necessitates exploratory laparotomy for peritonitis [8].

Improving imaging techniques have aided the clinicians in the diagnosis of hepatic abscesses and have subsequently become important treatment tools, decreasing the number of cases treated with surgical intervention. Furthermore, the demographics of the hepatic abscess have changed [9]. Though open surgery still remains most commonly used management modality, with advent of minimally invasive surgery, laparoscopic drainage of the ruptured abscess has been described with few complications. Thus, multiple management options are available today and ruptured liver abscess is a preventable and manageable pathology. However, what to do is decided by the clinicians based on the patient's medical status. No specific guidelines are available for choosing the modality of treatment. The purpose of this study is to see the efficacy of laparoscopic treatment in the management of intra-abdominal ruptured liver abscess. 


\section{Patients and Methods}

This is a retrospective observational study of patients with intra-abdominal ruptured liver abscess presenting to Cho Ray hospital between 2014 and 2018. The study was approved by the Hospital Ethical Board. All diagnosed cases of ruptured liver abscess based on radiology and laparoscopic investigation were included in the study. Details of demographics, clinical features, computed tomography were recorded. Also details of procedure, complications and outcome of laparoscopic surgical were recorded. Data will be analyzed using SPSS software.

\section{Laparoscopic Techniques}

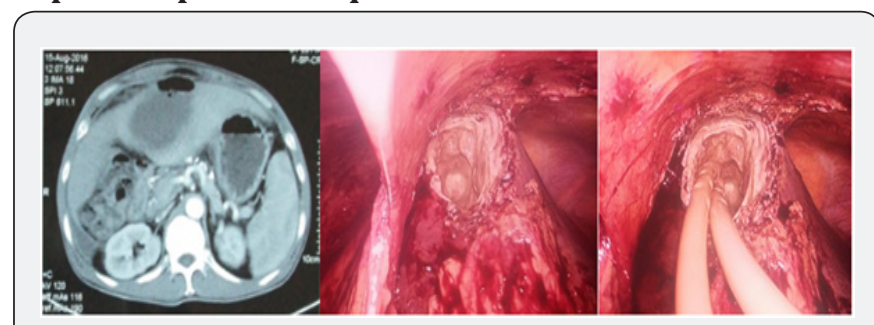

Figure 1: Percutaneous laparoscopic trocar drainage of ruptured liver abscess.

Under general anesthesia, initial peritoneal access for pneumoperitoneum was achieved usually with Veress needle through the umbilicus. Subsequently, a $10 \mathrm{~mm}$ laparoscope was introduced. Subsequent port positions depended on the pathology seen after the initial peritoneal exploration. Two $5 \mathrm{~mm}$ ports were usually placed at the left and right subcostal positions. The adhesions between the liver and the diaphragm as well as the anterior abdominal wall were freed to expose the area of the liver where the abscess was pointing. Aspiration of the cavity was done with Veress needle passed percutaneously or with suction nozzle; and in the process samples for bacterial cultures were taken. Finding of anchovy-sauce-like fluid supported the diagnosis of liver abscess. Thereafter, de-roofing of the cavity was done with electrocautery to enable insertion of a drainage catheter (Figure $1)$.

\section{Results}

\section{Clinical features}

Table 1: Clinical presentations of intra-abdominal ruptured liver abscess.

\begin{tabular}{|c|c|c|}
\hline Clinical Presentations & Frequency & Percentage (\%) \\
\hline Abdominal pain & 31 & 96.9 \\
\hline Malaise and anorexia & 31 & 96.9 \\
\hline Nausea / vomiting & 20 & 62.5 \\
\hline Fever $>38^{\circ} \mathrm{C}$ & 25 & 78.1 \\
\hline Jaundice & 5 & 15.6 \\
\hline Peritonitis & 25 & 78.1 \\
\hline Hepatomegaly & 4 & 12.5 \\
\hline
\end{tabular}

The study group consisted of 32 patients with a median age of $53.3 \pm 15.3$ years (range, 24-85 years). There were more men than women in the study, with a male-to-female ratio of 1.9:1.
Most of the patients were suffering from abdominal pain (96.9\%), malaise and anorexia (96.9\%), fever (78.1\%), peritonitis (78.1\%), and other positive clinical signs showed in Table 1.

\section{Liver CT characteristics}

The mean size of the liver abscess was $8.4 \mathrm{~cm}$ (range, 4.0-14 $\mathrm{cm}$ ). A single abscess was found in 11 patients, and multiple abscesses were seen in 21 patients. Unilobar involvement was seen in 29 patients, with the right lobe affected more commonly (68.8\%, 22 of 32). The abscesses were completely liquefied in 25 patients and gas in the abscess cavity in 7 patients. Free intraperitoneal fluid was seen in all patients. The liver CT characteristics of intraabdominal ruptured liver abscess was showed in Table 2.

Table 2: CT characteristics of intra-abdominal ruptured liver abscess.

\begin{tabular}{|c|c|}
\hline CT findings & All Patients (n=32) \\
\hline Abscess size $(\mathrm{cm})$ & $8.4(4.0-14)$ \\
\hline No. of abscesses & \\
\hline 1 & $21(34.4)$ \\
\hline$>1$ & \\
\hline Lobar involvement & $29(90.6)$ \\
\hline Unilobar & $3(9.4)$ \\
\hline Bilobar & $25(78.1 \%)$ \\
\hline Appearance & $7(21.9)$ \\
\hline Completely liquefied & $32(100 \%)$ \\
\hline Gas in the abscess cavity & \\
\hline Peritoneal effusion & \\
\hline
\end{tabular}

\section{Laparoscopic Management}

All patients received systemic antibiotic therapy before and after undergoing laparoscopic procedure. The antibiotics were ceftriaxone + metronidazole or carbapenem + metronidazole. The mean of operating time was $105 \pm 28$ minutes (median 100 minutes, range: 60 - 185 minutes). Time to pass gas after surgery was 2,8 $\pm 1,6$ days in average (range: $1-6$ days). The mean of time to remove drains was $10 \pm 5$ days (range: 3 - 27 days). The mean time of post-operative stay was $12,5 \pm 6,9$ days (rang: 3 30 days). Postoperative complications occurred in 8 patients (25.0\%) ( 3 cases of local ascite, 2 cases of pneumoniae, 1 case wound bleeding, 1 bile duct leak, 1 wound infection), and all complications were successfully managed in short time.

\section{Discussion}

Liver abscess is an important tropical gastrointestinal disorder $[10,11]$. Liver abscess can be classified into pyogenic and amebic, both having its serious implications, especially when presented late. In developing countries, it forms a major cause for mortality and morbidity $[12,13]$. With the advent of modern radiological modalities, diagnosis of hepatic abscess is possible in early stages resulting in nonsurgical management; however, fraction of patients either due to late presentation or refractory disease presents with ruptured liver abscess thereby increasing the mortality, presents with fatal disease course, and requires surgical intervention at the earliest $[8,14]$. 
Intraperitoneal rupture is one of the serious complications of liver abscesses [5,15-17]. The frequency of intraperitoneal rupture of a liver abscess varies from $2.5 \%$ to $17 \%$. Clinically, increasing hepatic tenderness should indicate an impending rupture [18]. The most common presentation was seen in our study include abdominal pain (96.9\%), malaise and anorexia (96.9\%), fever (78.1\%), peritonitis (78.1\%), nausea/vomiting (62.5\%), jaundice and hepatomegaly $(15.6 \%$ and $12.5 \%$, respectively). This results were comparable to study by Hind S. Alsaif with the most common presentation was fever and/or chills, followed by gastrointestinal symptoms (e.g., gastrointestinal upset, diarrhea, vomiting, nausea, discomfort, pain), respiratory symptoms (e.g., cough, dyspnea, chest distress), and jaundice [19].

Our results of liver CT characteristics were comparable to sutdy by Alexopoulou A et al, with the majority (69.7\%) of liver abscess involved the right lobe, they were $5-9 \mathrm{~cm}$ in size (63.6\%) and solitary (75.7\%). Multiple abscesses were observed in $24.2 \%$ of patients. The presence of elevated hemidiaphragm (42.4\%), pleural effusion $(18.2 \%)$ and basilar infiltrate $(6 \%)$ in chest radiography was also noted. Liver abscess was accompanied by pylephlebitis in 1 patient. Gas forming were observed in 4 patients (12.1\%) and loculated sub collections in the abscess in 3 (9\%) [3].

A single abscess was found in 54 (81.8\%) patients, and multiple abscesses were seen in $12(18.2 \%)$ patients in the study of Chang Z et al. [20]. Among the patients with multiple abscesses, the average number of lesions per patient was $2.5 \pm 0.67$. Unilobar involvement was seen in $54(81.8 \%)$ patients, and multilocular abscess was present in $50(75.8 \%)$ patients. The abscesses were predominantly solid in $38(57.6 \%)$ patients and cystic in 28 (42.4\%) patients. Thrombophlebitis was present in 9 (13.6\%) patients, and gas in the abscess cavity was present in 11 patients (16.7\%). There were $4(6.1 \%)$ patients with liver abscess who experienced a spontaneous rupture of the abscess [20].

With the development oflaparoscopic techniques, laparoscopic drainage may replace traditional open drainage in the treatment of liver abscess. A laparoscopic drainage group is better than an open drainage group in operation time, blood loss and length of hospital stay, and laparoscopic drainage is safe and feasible in patients who have no response to conservative treatment [2123]. All surgically accessible liver abscesses are candidates for laparoscopic drainage [23]. If a coexisting abdominal pathology is present that cannot be resolved by laparoscopy, then open surgery should be preferred.

Laparoscopic drainage of ruptured liver abscess has been successfully attempted. Laparoscopic method decreases the size of the incision and avoids the post-operative complications like burst abdomen commonly associated with open surgery for ruptured liver abscess. It also has the added advantage of being able to give ample peritoneal lavage and insight into other intra-abdominal pathology [24]. All patients in our study were successfully treated with laparoscopic surgery. These results ware compatible to study by Jin-Fu Tu et al. which showed in Table 3.
Table 3: Comparison results of laparoscopic surgery between our study and Jin-Fu Tu et al. [25].

\begin{tabular}{|c|c|c|}
\hline Variables & Jin-Fu Tu et al. [25] & $\begin{array}{c}\text { Our } \\
\text { study }\end{array}$ \\
\hline Operating time (min) & $117 \pm 27$ & $105 \pm 28$ \\
\hline Intraoperative blood loss (mL) & $139 \pm 51$ & \\
\hline $\begin{array}{c}\text { Intraoperative blood transfusion } \\
(\%)\end{array}$ & $1(7.7)$ & \\
\hline Commencement of oral intake (d) & $1.9 \pm 0.4$ & $2,8 \pm 1,6$ \\
\hline Postoperative complications (\%) & 15.4 & 25 \\
\hline Postoperative hospital stays (d) & $11.3 \pm 2.9$ & $12,5 \pm$ \\
6,9
\end{tabular}

Various reports have explored the laparoscopic approach in the management of liver abscesses [25,26]. Whereas it could be argued that this may be an unnecessarily expensive modality of treatment, the known benefits of minimally invasive surgery present a compelling response. It offers a middle ground between open surgical and percutaneous drainage. On one hand it helps in the early return of gastrointestinal function and resumption of normal activities; on the other hand, it potentially achieves a better abscess drainage [21,27]. More importantly laparoscopic drainage has been shown to be safe. There was neither mortality nor conversion to open surgery in our series, which is in line with other reports in the literature [22,23,27]. Adequate patient selection may partly be accountable for the very good results.

The value of a trained radiologist cannot be discounted for the successful conduct of percutaneous drainage. The procedure can have uncommon but serious complications [27-29]. Trained personnel may be a challenge in some developing countries, a reason for continued persistence with open surgical drainage. Accuracy of radiological diagnosis is also a problem in our environment. Doppler ultrasound and CT are not readily available. The case of liver hemangioma and carcinoma in our series should not have been misdiagnosed preoperatively. However, the recourse to laparoscopy may have obviated serious hemorrhagic complication. Utilization of laparoscopic ultrasonography may be another added advantage compared with transabdominal in localizing the abscess site for drainage [21-23].

\section{Conclusion}

A ruptured hepatic abscess is more life-threatening than an unruptured one. A rapid and accurate diagnosis and prompt surgical intervention are essential. Laparoscopic surgery has advantages in postoperative recovery of gastrointestinal function and length of postoperative hospital stay. Laparoscopic drainage is highly effective in management of large and freely ruptured abscess with decreased mortality, postoperative recovery and complications. It requires expertise and costly set up but nowadays, it is increasingly used and available.

\section{Competing Interests}

The authors declare that they have no competing interests. (Authors Contribution) 


\section{Acknowledgment}

The authors are grateful to physicians, administrative staff at Cho Ray Hospitals for allowing us to undertake this research.

\section{References}

1. Akhondi H, Sabih DE (2019) Liver Abscess. In: StatPearls Treasure Island (FL).

2. Chia DWJ, Kuan WS, Ho WH, Sim TB, Chua MT (2019) Early predictors for the diagnosis of liver abscess in the emergency department. Intern Emerg Med p.1-9.

3. Alexopoulou A, Dimopoulou H, Soultati A, Panetsos G, Dourakis SP (2010) Factors related to complications and mortality in pyogenic liver abscesses. Annals of Gastroenterology 23(4): 296-301.

4. Mukhopadhyay M, Saha AK, Sarkar A, Mukherjee S (2010) Amoebic liver abscess: presentation and complications. Indian J Surg. 72(1): $37-41$.

5. Satish KR, Sathyanarayana BA, Madhu SL, Nataraj NR, Amit GM, et al. (2015) A study of predictors for identification of risk of complications in patients with liver abscess. Trop Gastroenterol 36(2): 96-100.

6. Elechi EN, Etawo SU (1991) Management of intraperitoneal rupture of amoebic liver abscess: a 6-year experience with 11 cases in Port Harcourt, Nigeria. Trop Doct 21(1): 43-44.

7. Sarda AK, Bal S, Sharma AK, Kapur MM (1989) Intraperitoneal rupture of amoebic liver abscess. Br J Surg 76(2): 202-203.

8. Memon AS, Siddiqui FG, Memon HA, Ali SA (2010) Management of ruptured amoebic liver abscess: 22-years' experience. J Ayub Med Coll Abbottabad 22(2): 96-99.

9. Serraino C, Elia C, Bracco C, Rinaldi G, Pomero F, et al. (2018) Characteristics and management of pyogenic liver abscess: A European experience. Medicine (Baltimore) 97(19): e0628.

10. Cook GC (1991) Gastroenterological emergencies in the tropics Baillieres Clin Gastroenterol 5(4): 861-886.

11. Reeder MM (1975) Tropical diseases of the liver and bile ducts. Semin Roentgenol 10(3): 229-243.

12. Blessmann J, Van Linh P, Nu PA, Thi HD, Muller-Myhsok B, et al. (2002) Epidemiology of amebiasis in a region of high incidence of amebic liver abscess in central Vietnam. Am J Trop Med Hyg 66(5): 578-583.

13. Kannathasan S, Murugananthan A, Kumanan T, de Silva NR, Rajeshkannan N, et al. (2018) Epidemiology and factors associated with amoebic liver abscess in northern Sri Lanka. BMC Public Health. 18(1): 118.
14. Short M, Desai AP (2008) Laparoscopy and transdiaphragmatic thoracoscopy in management of ruptured amebic liver abscess. J Laparoendosc Adv Surg Tech A 18(3): 473-476.

15. Adams EB, MacLeod IN (1977) Invasive amebiasis. II. Amebic liver abscess and its complications. Medicine (Baltimore) 56(4): 325-334.

16. Jolobe OM (2010) Intrahepatic expansion of amebic liver abscess can also generate life-threatening complications. South Med J. 103(11): 1189-1190.

17. Munoz LE, Botello MA, Carrillo O, Martinez AM (1992) Early detection of complications in amebic liver abscess. Arch Med Res. 23(2): 251253.

18. Eggleston FC, Handa AK, Verghese M (1982) Amebic peritonitis secondary to amebic liver abscess. Surgery 91(1): 46-48.

19. Alsaif HS, Venkatesh SK, Chan DS, Archuleta S (2011) CT appearance of pyogenic liver abscesses caused by Klebsiella pneumoniae. Radiology 260(1): 129-138.

20. Chang Z, Zheng J, Ma Y, Liu Z (2015) Analysis of clinical and CT characteristics of patients with Klebsiella pneumoniae liver abscesses: an insight into risk factors of metastatic infection. Int J Infect Dis 33: 50-54.

21. Aydin C, Piskin T, Sumer F, Barut B, Kayaalp C (2010) Laparoscopic drainage of pyogenic liver abscess. JSLS 14(3): 418-420.

22. Cioffi L, Belli A, Limongelli P, Russo G, Arnold M, D’Agostino A, et al (2014) Laparoscopic Drainage as First Line Treatment for Complex Pyogenic Liver Abscesses. Hepatogastroenterology 61(131): 771-775.

23. Wang W, Lee WJ, Wei PL, Chen TC, Huang MT (2004) Laparoscopic drainage of pyogenic liver abscesses. Surg Today 34(4): 323-5.

24. Siu WT, Chan WC, Hou SM, Li MK (1997) Laparoscopic management of ruptured pyogenic liver abscess. Surg Laparosc Endosc. 7(5): 426-428.

25. Tu JF, Huang XF, Hu RY, You HY, Zheng XF, et al. (2011) Comparison of laparoscopic and open surgery for pyogenic liver abscess with biliary pathology. World J Gastroenterol 17(38): 4339-4343.

26. Ng SS, Lee JF, Lai PB (2008) Role and outcome of conventional surgery in the treatment of pyogenic liver abscess in the modern era of minimally invasive therapy. World J Gastroenterol 14(5): 747-751.

27. Tan L, Zhou HJ, Hartman M, Ganpathi IS, Madhavan K, et al. (2013) Laparoscopic drainage of cryptogenic liver abscess. Surg Endosc 27(9): 3308-3314.

28. Cappuccino H, Campanile F, Knecht J (1994) Laparoscopy-guided drainage of hepatic abscess. Surg Laparosc Endosc 4(3): 234-237.

29. Lorenz J, Thomas JL (2006) Complications of percutaneous fluid drainage. Semin Intervent Radiol 23(2): 194-204.

\section{Your next submission with Juniper Publishers will reach you the below assets}

- Quality Editorial service

- Swift Peer Review

- Reprints availability

- E-prints Service

- Manuscript Podcast for convenient understanding

- Global attainment $f$ or your research

- Manuscript accessibility in different formats

( Pdf, E-pub, Full Text, Audio)

- Unceasing customer service

Track the below URL for one-step submission https://juniperpublishers.com/online-submission.php 